\title{
Poignant tales of refugees in Canada
}

\author{
Safe and Sound? \\ Hans Christian Berger, Director \\ Susan Nouch, Jill Cunes, Producers \\ UBC Department of Family Practice; 2010
}

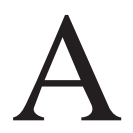

ccess to health services is a leading concern for all Canadians. Migrants - in particular newly arriving refugees who are struggling to learn English or French and have no social networks in Canada experience the full force of phone lines that ring busy and brick-wall receptionists who are reluctant to make appointments for new patients.

A new award-winning 30-minute film, Safe and Sound?, from Hans Christian Berger and the Department of Family Practice at the University of British Columbia in Vancouver captures the poignant stories of transition of newly arriving refugees in Vancouver (http://safeandsoundfilm.com). Refugee clinics have emerged in many of Canada's urban centres to provide health settlement to increasingly diverse and medically complex refugees from around the world. The Bridge Clinic, featured in Safe and Sound?, is a leader among these clinics, converting international health currency into Canadian health currency through primary and preventive health care, mental health support and helping refugees to locate a long-term family physician. And, as Dr. Maureen Mayhem, medical coordinator of the Bridge Clinic, says, this final step of "locating a family physician, continues to be a huge challenge."

Safe and Sound? uses the voices of five newly arriving refugees: Hojjat from Iran, Joy from Burma, Bek from Uzbekistan, Brenda from Uganda, and Zainab from Iraq, piecing together their refugee experiences and in doing so exposing challenges of transition to life in Vancouver. The transition that follows leaving "everything behind" as
Zainab says, and as Hojjat says, rebuilding your life after "suddenly everything falls down."

Within these interlocking stories, professionals deal with loss of status, role reversals, challenges inherent in adapting to a new culture and learning a new language, and integrating into an imperfect health system. The film captures the wonderful smile of Hojjat, an engaging Azerbaijan-Turk actor whose gentle nature forms the heart of this film, and the inspiring resilience of Bek, a tortured and imprisoned Uzbek journalist who says "as soon as I close my eyes everything would return," but who continues to write and stay active through the Internet.

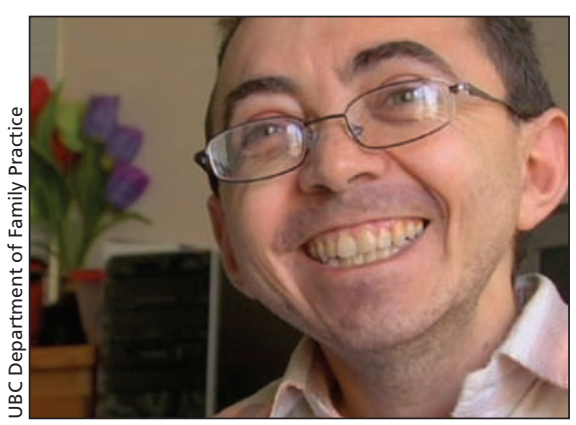

Hojjat, an Azerbaijan-Turk actor and political refugee, is particularly engaging.

At times there is a sense that these refugees remain lost in transition, and this is the one element of this film that I found unfortunate. In honing in on the transition period of newly arriving refugees, it forfeits the opportunity to show the success stories that frequently only emerge after many years in Canada. Successes such as buying their first house in Canada, watching their children enter university, returning home to visit friends and family, and discovering a way to put their professional training and passions to use either in Canada or in helping those left behind.

Canadian philosopher Will Kymlicka advocates for distinct rights for special groups: indigenous, immigrants, and minority language groups. He reasons that these distinct rights enable these groups to become full participants in a liberal democracy; that these rights remedy often unrecognized challenges of minority groups. Unrecognized, that is, by individuals who speak the majority language, whose schools teach the history of their ancestors and whose holidays coincide with their religious holidays. Safe and Sound? shows us some of these often overlooked challenges, such as the need for medical interpretation, that Canada's health system must strive to address.

In the film, Berger succeeds in capturing the rich human experiences of each of his subjects. In so doing, he implicitly challenges Canadian physicians to keep pace with population mobility and the challenges of practicing medicine in the global village. The film also shows how working with newly arriving migrants can provide a portal to discovering the diverse cultures of the world.

Migration medicine is emerging as a new interest area for many family physicians and one can easily imagine that after working with refugees like Bek or Joy or Hojjat, accepting refugee patients becomes a privilege rather than a hardship. As one of the family doctors in the film says, in "Nepalese there isn't a word for depression" and so you have to find new ways to ask about and treat suffering and illness. Canada has a reputation as a compassionate and open country but as Safe and Sound? demonstrates, our health system and our practitioners will need to continue to rise to new heights for us to keep this reputation.

\section{Kevin Pottie MD}

Associate professor

Departments of Epidemiology and

Community Medicine

University of Ottawa

Ottawa, Ontario

CMAJ 2011. DOI:10.1503/cmaj.101559 